\title{
Cardioprotection after acute exposure to simulated high altitude in rats. Role of nitric oxide
}

\author{
Pablo H. La Padula ${ }^{\mathrm{a}, *}$, Melisa Etchegoyen ${ }^{\mathrm{a}}$, Analia Czerniczyniec ${ }^{\mathrm{b}}$, Barbara Piotrkowski ${ }^{\mathrm{b}}$, \\ Silvia Lores Arnaiz ${ }^{\mathrm{b}}$, Jose Milei ${ }^{\mathrm{a}}$, Lidia E. Costa ${ }^{\mathrm{a}}$ \\ a Institute of Cardiological Research, School of Medicine, University of Buenos Aires, National Research Council of Argentina, 1122 Buenos Aires, Argentina \\ ${ }^{\mathrm{b}}$ Institute of Biochemistry and Molecular Medicine (IBIMOL; UBA-CONICET), School of Pharmacy and Biochemistry, University of Buenos Aires, 1122 Buenos Aires, \\ Argentina
}

\section{A R T I C L E I N F O}

\section{Keywords:}

Acute hypobaric hypoxia

$\beta$-Adrenergic response

Cardioprotection

High altitude

Nitric oxide

\begin{abstract}
A B S T R A C T
Aim: In previous studies, upregulation of NOS during acclimatization of rats to sustained hypobaric hypoxia was associated to cardioprotection, evaluated as an increased tolerance of myocardium to hypoxia/reoxygenation. The objective of the present work was to investigate the effect of acute hypobaric hypoxia and the role of endogenous NO concerning cardiac tolerance to hypoxia/reoxygenation under $\beta$-adrenergic stimulation.

Methods: Rats were submitted to $58.7 \mathrm{kPa}$ in a hypopressure chamber for $48 \mathrm{~h}$ whereas their normoxic controls remained at $101.3 \mathrm{kPa}$. By adding NOS substrate L-arg, or blocker L-NNA, isometric mechanical activity of papillary muscles isolated from left ventricle was evaluated at maximal or minimal production of NO, respectively, under $\beta$-adrenergic stimulation by isoproterenol, followed by 60/30 min of hypoxia/reoxygenation. Activities of NOS and cytochrome oxidase were evaluated by spectrophotometric methods and expression of HIF1- $\alpha$ and NOS isoforms by western blot. Eosin and hematoxiline staining were used for histological studies. Results: Cytosolic expression of HIF1- $\alpha$, nNOS and eNOS, and NO production were higher in left ventricle of hypoxic rats. Mitochondrial cytochrome oxidase activity was decreased by hypobaric hypoxia and this effect was reversed by L-NNA. After H/R, recovery of developed tension in papillary muscles from normoxic rats was $51-60 \%$ (regardless NO modulation) while in hypobaric hypoxia was 70\% \pm 3 (L-arg) and 54\% \pm 1 (L-NNA). Other mechanical parameters showed similar results. Preserved histological architecture was observed only in Larg papillary muscles of hypoxic rats.

Conclusion: Exposure of rats to hypobaric hypoxia for only 2 days increased NO synthesis leading to cardioprotection.
\end{abstract}

\section{Introduction}

Hypoxic states of the cardiovascular system are undoubtedly associated with the most frequent diseases of modern times. Reduced oxygen supply with adequate perfusion to the myocardium can be observed in diverse conditions, such as cor pulmonale, congenital heart disease, and high altitudes. In the myocardium of subjects living permanently at high altitudes, systemic hypoxia can be qualified as physiological [1-3].

In our laboratory, a model of sustained hypobaric hypoxia which simulates high altitude hypoxia under environmental and hereditary controlled conditions has been developed [4-6]. Results showed that acclimatization to simulated altitude delayed the age-associated decline in the functional capacity of rat myocardium and improved its recovery after hypoxia and reoxygenation, determined in isolated papillary muscle from the left ventricle [2]. Cardioprotection conferred by our model lasted markedly longer, following removal of the stimulus than that achieved by the thoroughly studied phenomenon of ischemic preconditioning [7], intermittent hypobaric hypoxia [8] or pharmacological treatments. The cardioprotective effects presented a linear decline during deacclimatization, with mean half-time of 5.5 months (mo) for the total normalization of the response, persisting even after the

\footnotetext{
Abbreviations: NO, nitric oxide; NOS, nitric oxide synthase; nNOS, neuronal nitric oxide synthase; eNOS, endothelial nitric oxide synthase; iNOS, inducible nitric oxide synthase; L-arg, L-

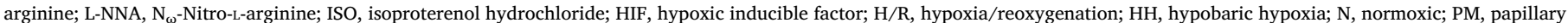
muscles; LV, left ventricle; DT, developed tension; + T, maximal velocity of contraction; -T, maximal velocity of relaxation; SEM, standard error of the mean

* Corresponding author. Instituto de Investigaciones Cardiológicas, Marcelo T de Alvear 2270, C1122AAJ Buenos Aires, Argentina.

E-mail addresses: pablolapa@gmail.com (P.H. La Padula), mberisso@gmail.com (M. Etchegoyen), anaczerni@gmail.com (A. Czerniczyniec), barbara@ffyb.uba.ar (B. Piotrkowski), slarnaiz@ffyb.uba.ar (S.L. Arnaiz), josemilei@gmail.com (J. Milei), lecosta@fmed.uba.ar (L.E. Costa).
} 
regression of other hypoxia-induced changes such as polycythemia, pulmonary hypertension and right ventricle hypertrophy [9]. Indeed, resistance to myocardial ischemia was increased in rabbits raised from birth to 10 days of age in a hypoxic $\left(12 \% \mathrm{O}_{2}\right)$ environment [10]. Moreover, isolated hearts from mice submitted to $10 \% \mathrm{O}_{2}$ for $4 \mathrm{~h}$ were resistant to infarction $24 \mathrm{~h}$ later [11]. In both cases the effect was associated to an enhanced cytosolic NOS activity. The duration, frequency, and severity of hypoxic episodes become critical factors determining whether hypoxia could be harmful [12], or paradoxically beneficial $[2,3,13]$.

Endogenous NO plays a fundamental role in protecting the heart against both reversible (myocardial stunning) and irreversible (myocardial infarction) ischemia/reperfusion injury [3,14]. The three main isoforms of NO synthase, namely, neuronal NOS (nNOS), endothelial NOS (eNOS), and the inducible NOS (iNOS), were reported to be involved in cardioprotection by systemic acute and chronic hypoxia [11,15-17]. During acclimatization to sustained hypobaric hypoxia, an increased NOS protein expression in mitochondrial fraction of left ventricle was associated to the preservation of papillary muscle contractile parameters and tolerance to $\mathrm{O}_{2}$ deprivation [2,13], whereas during deacclimatization the normalization time of NOS activity and expression paralleled the decline in the cardioprotective effects [9]. NO effects depend, among others, on NO concentration [9], compartmentalization of NOS enzymes and local redox conditions of cells and tissues [14].

Many evidences collected by both in vivo and in vitro experiments suggest a crosstalk between NO and adrenergic receptors [18-20]. In vascular endothelial cells NO generated by eNOS acts a signaling molecule and one of its main functions is to cause vasodilatation via cGMP, whereas stimulation of $\beta$-adrenergic receptors increases vascular tone via cAMP. Both important cell-signaling systems play a role in modulation of contractility and are interconnected, being NO production directly linked to stimulation of $\beta$-adrenoceptors in many instances $[18,21]$. Within the myofibrils or the myocytes of the ventricular wall, contractility is mainly modulated by intracellular transient $\mathrm{Ca}^{2+}$ availability, which is increased by both the $\beta$-adrenergic and the NO generated by nNOS systems [22], stimulating the opening of L and RyR $\mathrm{Ca}^{2+}$ channels through phosphorylation and nitrosylation, respectively [14,23]. Furthermore, NO inhibits cytochrome oxidase, modulating ATP availability for contractility $[9,24]$. On the other hand, the $\beta$ adrenergic system, which contributes to regulate the blood pressure, has been implicated in a cardioprotective model when has been stimulated [25,26]. This topic seems to be important, because many cardiac patients are treated with $\beta$-blockers to control the arterial pressure, which is often increased by exposure to hypoxic hypobaric environment $[27,28]$.

The aim of the present study was to evaluate the effect of acute hypobaric hypoxia $(\mathrm{HH})$ and the role of endogenous NO in the modulation of cardiac $\beta$-adrenergic stimulation and tolerance to hypoxia/ reoxygenation $(H / R)$. For this purpose, in papillary muscles $(\mathrm{PM})$ from left ventricles of rats submitted to $\mathrm{HH}$, mechanical activity was sequentially determined under basal conditions, and at maximal and minimal production of NO in response to $\beta$-adrenergic stimulation and during H/R. Furthermore, left ventricle (LV) cytosolic NOS expression and activity, HIF-1 $\alpha$ expression, histological status and blood pressure were evaluated.

\section{Methods}

\subsection{Experimental design}

Three mo-old male Wistar rats of the CHbbTHOM albino strain ( $\mathrm{n}=10$ ) were submitted during $48 \mathrm{~h}$ to a simulated altitude of $4400 \mathrm{~m}$ $(58.7 \mathrm{kPa}=440 \mathrm{mmHg})$ in a hypopressure chamber as previously described [29], whereas the same number of sibling rats $(n=10)$ remained as controls at sea level atmospheric pressure
$(101.3 \mathrm{kPa}=760 \mathrm{mmHg})$. Food and water were administered ad-libitum. Pressure changes were achieved slowly, and the renewal of air in the chamber was sufficient to ensure the composition of atmospheric air. The partial pressure of $\mathrm{O}_{2}$ in the inspired air was, therefore, $12.3 \mathrm{kPa}=92 \mathrm{mmHg}$ and $21.2 \mathrm{kPa}=159 \mathrm{mmHg}$, for hypoxic and control rats, respectively. Both groups were maintained at the same temperature $\left(22^{\circ} \mathrm{C}\right)$ on a schedule of $12 \mathrm{~h}$ of light and $12 \mathrm{~h}$ of dark. Systolic blood pressure was recorded before and after the hypobaric exposure in a similar group of awake rats at $30^{\circ} \mathrm{C}$ by tail plethysmography, using a NIBP controller module in conjunction with a Power Lab system (AD Instruments, USA). Recordings were stored and analyzed using Lab Chart software (AD Instruments). Rats received care in accordance with the 6344/96 regulation of the Argentinean National Drug, Food, and Medical Technology Administration (ANMAT) and the study was carried out in accordance with the "Guide for the Care and Use of Laboratory Animals" prepared by the Institute of Laboratory Animal Research and published by the National Institutes of Health (NIH Publications No. 8023, revised 1978).

\subsection{Heart muscle preparations}

Immediately after removing hypoxic rats from the hypobaric chamber as well as in controls, the thorax was opened under anesthesia with penthobarbital overdose of $60 \mathrm{mg} / \mathrm{kg}$, the heart was excised, rinsed and transferred to Ringer solution of the following composition (in $\mathrm{mM}$ ): $128.3 \mathrm{NaCl}, 4.7 \mathrm{KCl}, 20.2 \mathrm{NaHCO}_{3}, 0.35 \mathrm{NaH}_{2} \mathrm{PO}_{4}, 1.05$ $\mathrm{MgSO}_{4}, 1.35 \mathrm{CaCl}_{2}$, and 5.5 glucose, $\mathrm{pH} 7.4$, flushed with $95 \% \mathrm{O}_{2}-5 \%$ $\mathrm{CO}_{2}$, at $30^{\circ} \mathrm{C}$. The left ventricle was opened, and both papillary muscles were removed while submerged in buffer. The chordae end of each muscle was tied with 10-0 nylon suture, which was attached to a Statham force transducer and 9853 coupler (Gould-Statham) mounted on a movable support controlled by a micrometer for accurate length adjustment. The bottom end of each papillary muscle was inserted into a stainless steel spring clip, and the muscles were mounted vertically in two temperature-controlled chambers containing $30 \mathrm{ml}$ of the Ringer solution each one. The solutions were equilibrated with a mixture of $95 \% \mathrm{O}_{2}$ and $5 \% \mathrm{CO}_{2}$, with $\mathrm{pH}$ and temperature kept constant at 7.4 and $30{ }^{\circ} \mathrm{C}$, respectively [22]. The heart, trimmed of atria and large vessels, was dissected into the left ventricle plus septum (LV) and right ventricle (RV), which were weighed separately [29].

\subsection{Papillary muscle mechanical activity}

Papillary muscles (total $n=40$ ) were allowed to stabilize for $45 \mathrm{~min}$ after mounting. Rectangular pulses of $10 \mathrm{~ms}$ with an amplitude $20 \%$ higher than the threshold of each preparation were digitally delivered by means of a stimulator controlled by a data acquisition and analysis software (FPE). Contraction frequency was kept constant at 12 beats $\min ^{-1}$. The muscles were then stretched until maximal developed tension occurred. The isometric mechanograms were recorded on a Beckman R511A connected to the force transducer, and simultaneously the computer utilizing FPE digitized and stored the force-pacing signal for later analysis. Maximal developed tension (DT), maximal rate of rise in DT $(+\mathrm{T})$, and maximal velocity of relaxation $(-\mathrm{T})$ were determined. Each data result was the mean of three successive twitches (38). After recording the basal contractility, papillary muscles (PM) were incubated $10 \mathrm{~min}$ with $2 \mathrm{mM} \mathrm{L}$-arg, a NOS substrate, to obtain the maximal endogenous NO production or with $2 \mathrm{mM}$ L-NNA, a NOS blocker, to obtain the minimum production of endogenous NO. Controls were performed at the same conditions but without NOS substrate or blocker. The three subgroups were then $\beta$-adrenergic stimulated with $0.1 \mathrm{mM}$ isoproterenol hydrochloride (ISO). A 60-min period of hypoxia was then established by using a gas mixture of $95 \% \mathrm{~N}_{2}$ and $5 \% \mathrm{CO}_{2}$, followed by a 30-min period of reoxygenation $\left(95 \% \mathrm{O}_{2}\right.$ and $\left.5 \% \mathrm{CO}_{2}\right)$, and mechanical events were recorded every $10 \mathrm{~min}$ (Fig. 1). At the end of each experiment, muscles length was measured with a caliper. The 
(a)

\begin{tabular}{|c|c|c|c|}
\hline control & ISO & hypoxia & reoxygenation \\
\hline 离 L-arg & ISO & hypoxia & reoxygenation \\
\hline ¿ L-NNA & ISO & hypoxia & reoxygenation \\
\hline control & ISO & hypoxia & reoxygenation \\
\hline L-arg & ISO & hypoxia & reoxygenation \\
\hline$\stackrel{\infty}{\infty}$ L-NNA & ISO & hypoxia & reoxygenation \\
\hline 10 & 10 & 60 & 30 \\
\hline
\end{tabular}

Fig. 1. Experimental design. a: papillary muscles from normoxic rats; b: papillary muscles from rats submitted $48 \mathrm{~h}$ to hypobaric hypoxia. Control $(n=6)$, L-arg $(n=7)$, L-NNA $(n=7)$ in each subgroup. ISO: $0.1 \mathrm{mM}$ isoproterenol; L-arg $2 \mathrm{mM}$ and L-NNA $2 \mathrm{mM}$.
PM were then blotted dry and weighed, and cross-sectional area of each one was calculated, assuming the muscle to be a cylinder with a density of 1.0. Mechanical parameters were normalized for muscle cross-sectional area [9].

\subsection{Histological analysis}

Once papillary muscles were removed, the remnant cardiac tissue underwent formalin fixation. After inclusion in paraffin, the hearts were cut horizontally into one central block between the base and apex. The block was dehydrated through a graded series of ethanol solutions (70-100\%), cleaned with xylene at room temperature, and embedded in paraffin at $60^{\circ} \mathrm{C}$ for $2 \mathrm{~h} 3$ times. Paraffin blocks were stored at $4{ }^{\circ} \mathrm{C}$ until sectioning. For light microscopy, heart sections ( $3 \mu \mathrm{m}$ thickness) were prepared serially and stained with hematoxylin and eosin. Histological changes of the whole heart and the papillary muscles were observed under a light microscope to detect recent ischemic myocardial changes. A Nikon Eclipse 50i microscope (Nikon Corporation, Tokyo, Japan), equipped with a digital camera (Nikon Coolpix S4) and the Image-Pro Plus image processing software version 6.0 (Media Cybernetics, Silver Spring, Maryland, USA) were used.

\subsection{Isolation of left ventricle cytosolic and mitochondrial fractions}

Left ventricles deprived of the papillary muscles were weighed, chopped, and homogenized in an ice-cold homogenization medium (1:10) containing $0.23 \mathrm{M}$ mannitol, $0.07 \mathrm{M}$ sucrose, $10 \mathrm{mM}$ Tris- $\mathrm{HCl}$, and $1 \mathrm{mM}$ EDTA, pH 7.4, for $30 \mathrm{~s}$ with a blade homogenizer (KendroSorvall-Du Pont Institute, Asheville, NC) and by five strokes in a glass Teflon homogenizer. All these operations were carried out at $2-4{ }^{\circ} \mathrm{C}$. The homogenates were centrifuged at $700 \mathrm{~g}$ for $10 \mathrm{~min}$ to discard nuclei and cell debris, and the supernatant was centrifuged at $8000 \mathrm{~g}$ for $10 \mathrm{~min}$. The supernatant, containing the cytosolic fraction, was separated from the mitochondrial pellet. Mitochondrial pellet was washed and resuspended in the same buffer at a protein concentration of $20-25 \mathrm{mg}$ / $\mathrm{ml}$. Submitochondrial membranes were obtained by twice freezing and thawing the mitochondrial preparation and were homogenized by passage through tuberculine syringe with a needle. Protein concentration was determined with the Folin reagent and bovine serum albumin as standard.

\subsection{Nitric oxide production}

Production of NO was measured in cytosolic fractions from left ventricles by following the oxidation of oxyhaemoglobin $\left(\mathrm{HbO}_{2}\right)$ to methaemoglobin (metHb) at $37^{\circ} \mathrm{C}$. The NO assay was performed using a Beckman-Coulter Serie DU 7400 diode array spectrophotometer in which the active wavelength is set at $577 \mathrm{~nm}$ and the reference wavelength at the isosbestic point at $591 \mathrm{~nm}\left(\varepsilon=11.2 \mathrm{mM}^{-1} \mathrm{~cm}^{-1}\right)$ [30]. The method is based on the original assay developed by Murphy and Noack [29] for perfused organs in which the $\mathrm{HbO}_{2} \gamma$ band is used to follow NO production. The $\alpha$ band is more suitable for high light scattering conditions of cellular and mitochondrial suspensions due to the close vicinity of the active $(577 \mathrm{~nm})$ and the reference $(591 \mathrm{~nm})$ wavelengths [30]. The measurements were carried out in a reaction medium containing $50 \mathrm{mM}$ phosphate buffer $\mathrm{pH} 7.4,1 \mathrm{mM} \mathrm{CaCl}$, $50 \mu \mathrm{M}$ L-arginine, $100 \mu \mathrm{M}$ NADPH, $10 \mu \mathrm{M}$ DTT, $4 \mu \mathrm{M}$ Cu-Zn superoxide dismutase (SOD), $0.1 \mu \mathrm{M}$ catalase, cytosolic fractions $(0.5-1.0 \mathrm{mg}$ protein/ml) and $25 \mu \mathrm{M}$ oxyhaemoglobin (expressed per heme group). Controls adding $0.5 \mathrm{mM} \mathrm{N}_{\omega}$-nitro-L-arginine (L-NNA) as NOS inhibitor were performed in all cases to give specificity to the assay.

\subsection{Expression of HIF-1 $\alpha$, eNOS and nNOS}

Equal amounts of cytosolic protein $(80 \mu \mathrm{g})$ or mitochondria $(60 \mu \mathrm{g})$ were loaded into SDS-PAGE (7.5\% or 15\%), separated and blotted onto nitrocellulose membranes in Tris-glycine-MeOH buffer. Non-specific binding was blocked by incubation of the membranes with $5 \%$ non-fat dry milk in PBS for $1 \mathrm{~h}$ at room temperature. The blots were probed with a dilution 1:500 of polyclonal primary antibodies specific for nNOS (rabbit, amino terminus, H-299, Santa Cruz Biotechnology, Santa Cruz, CA, USA), eNOS (rabbit, amino terminus, N-20, Santa Cruz Biotechnology, Santa Cruz, CA, USA), VDAC (goat, N-18, Santa Cruz Biotechnology, Santa Cruz, CA, USA) or $\beta$-tubulin (mouse): ab131205, Abcam. Primary antibodies were incubated in $1 \%$ BSA in PBS overnight at $4{ }^{\circ} \mathrm{C}$ with rocking. The blots were rinsed three times for $15 \mathrm{~min}$ with PBST (PBS with $0.15 \%$ Tween 20) and then incubated with horseradish peroxidase-conjugated secondary antibodies (anti-rabbit or anti-goat) at 1:5000 in $2.5 \%$ non-fat dry milk in PBS for $1 \mathrm{~h}$ at room temperature with rocking. The blots were rinsed three times for $10 \mathrm{~min}$ with PBS and then exposed with ECL reagent. In the case of HIF, primary antibody against HIF-1 $\alpha$ (goat, C terminus, C-19, Santa Cruz Biotechnology, Santa Cruz, CA, USA) in a dilution 1:500 was used. Biotin conjugated secondary anti-goat (Code: RPN1025V, GE healthcare, Buckingham, UK) and streptavidin-horse radish peroxidase complex (Code: RPN1051, GE healthcare, Buckingham, UK) were used at 1:10000 dilution. Densitometric analysis of bands was performed using the NIH Image 1.54 software. All experiments were performed in triplicate.

\subsection{Cytochrome oxidase activity (complex IV) was assayed spectrophotometrically at $550 \mathrm{~nm}$ by following the rate of oxidation of reduced cytochrome c [13]}

Cytochrome $c$ was reduced with dithionite that was removed afterwards by eluting through a Sephadex-G25 column with potassium phosphate buffer $(10 \mathrm{mM}), \mathrm{pH}$ 7.4. The reaction was initiated by the addition of $50 \mu \mathrm{M}$ reduced cytochrome $c$ to submitochondrial membranes $(0.5 \mathrm{mg} / \mathrm{ml})$ and the rate of reduced cytochrome $c$ oxidation was determined as a pseudo-first-order reaction constant ( $\left.k^{\prime}\right)$ [expressed as $\mathrm{k}$ '/mg protein].

\subsection{Statistics}

Results are expressed as mean values \pm SE. One-way ANOVA plus the post ANOVA Bonferroni $t$-test for multiple comparisons were used for statistical analysis of the data as appropriate (Microcal Origin 6.0 statistical software). A value of $\mathrm{p}<.05$ was considered statistically significant. 
Table 1

Biological parameters of rats submitted $48 \mathrm{~h}$ to $58.7 \mathrm{kPa}(\mathrm{HH})$ and of their controls at $101.3 \mathrm{kPa}(\mathrm{N})$.

\begin{tabular}{|c|c|c|c|c|c|c|}
\hline Group & $\begin{array}{l}\text { Body weight } \\
\text { (g) }\end{array}$ & $\begin{array}{l}\text { Heart weight } \\
(\mathrm{g})\end{array}$ & Left ventricle weight (g) & $\begin{array}{l}\text { Right ventricle } \\
\text { weight }(\mathrm{g})\end{array}$ & Papillary muscle area $\left(\mathrm{mm}^{2}\right)$ & $\begin{array}{l}\text { Arterial pressure } \\
(\mathrm{mmHg})\end{array}$ \\
\hline $\mathrm{N}$ & $457 \pm 3$ & $1.13 \pm 0.06$ & $0.89 \pm 0.06$ & $0.24 \pm 0.06$ & $1.2 \pm 0.1$ & $136 \pm 2$ \\
\hline $\mathrm{HH}$ & $427 \pm 9^{*}$ & $1.10 \pm 0.06$ & $0.90 \pm 0.06$ & $0.20 \pm 0.06$ & $1.2 \pm 0.1$ & $139 \pm 2$ \\
\hline
\end{tabular}

Values are means $\pm \mathrm{SE} ; \mathrm{n}=10$ rats in each group (20 papillary muscles). $\mathrm{HH}$, rats submitted to $58.7 \mathrm{kPa}, 48 \mathrm{~h} ; \mathrm{N}$, controls at $101.3 \mathrm{kPa}$. ${ }^{*} P<.05$.

\section{Results}

\subsection{Biological parameters}

After $48 \mathrm{~h}$ of exposure to $4400 \mathrm{~m}$ simulated altitude body weight was $7 \%$ lower, whereas ventricles weight, papillary muscles area and arterial pressure were similar to the normoxic group (Table 1).

\subsection{Expression of HIF-1 $\alpha$}

Expression of HIF-1 $\alpha$ was evaluated because of its relevance as biochemical regulator of oxygen homeostasis increasing in acute hypoxia. After $48 \mathrm{~h}$ of hypobaric hypoxia the ratio of protein expression of HIF- $1 \alpha / \beta$-tubulin was $32 \%$ higher in cytosolic left ventricles, as compared with normoxic rats, $p<.05$ (Fig. 2).

\subsection{Expression of NOS and NO production}

In the conditions of the assay, the left ventricle cytosol from normoxic and hypoxic groups reacted differentially with anti-eNOS, and anti-nNOS antibodies. The densitometric quantification of the Western Blot spots indicated a higher level of expression of cytosolic eNOS $(53 \%)$ and nNOS (76\%) in the hypoxic group than in normoxic rats, $p<.05$ (Fig. 3a). The rates of NO production were measured in cytosolic fractions from left ventricles. In normoxic rats, production rate was $0.28 \pm 0.02 \mathrm{nmol} \mathrm{NO} \mathrm{min}^{-1} \mathrm{mg}$ protein ${ }^{-1}$. After $48 \mathrm{~h}$ of hypobaric hypoxia, cytosolic NO production was significantly increased $(32 \%)$ to $0.37 \pm 0.04 \mathrm{nmol} \mathrm{NO} \mathrm{min}^{-1} \mathrm{mg}$ protein ${ }^{-1}, p<.05$ (Fig. 3 b). Mitochondrial expression shown as the ratio of densitometric units NOS/VDAC tended to increase (11\%) for nNOS in the hypoxic group although this result was not statistically significant $(\mathrm{N}: 0.74 \pm 0.03$; HH: $0.82 \pm 0.08$ ); eNOS expression was similar for both normoxic and hypoxic groups $(\mathrm{N}: 0.86 \pm 0.05, \mathrm{HH}: 0.87 \pm 0.10)$.

\subsection{Cytochrome oxidase activity (complex IV)}

In the normoxic group, mitochondrial cytochrome oxidase activity was not significantly affected by the addition of NOS substrate L-arg or inhibitor L-NNA. After $48 \mathrm{~h}$ of hypobaric hypoxia cytochrome oxidase activity was $27 \%$ decreased in control conditions, while it was $24 \%$ decreased in the presence of L-arg. These changes in cytochrome oxidase activity in the hypoxic groups were abolished when the assay was carried out in the presence of L-NNA (Fig. 4).

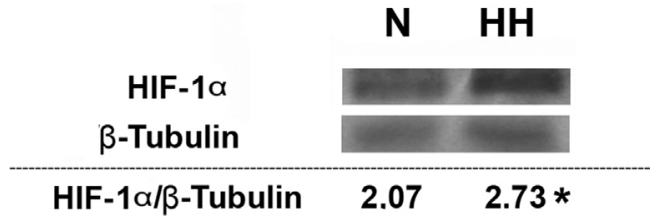

Fig. 2. Left ventricle cytosolic HIF- $\alpha 1$ expression. N: normoxic group; HH: hypobaric hypoxia $48 \mathrm{~h}$. Ratio HIF-1 $\alpha / \beta$-tubulin expressed in densitometric units. Paired $t$-test twotailed, $* P<.05$; SE of the difference $=0.12$.

\subsection{Basal contractile parameters and modulation by NO}

The basal contractile parameters, developed tension and maximal rates of contraction and relaxation, which in papillary muscles preparations are vascular tone independent, were similar in rats exposed to $48 \mathrm{~h}$ of simulated high altitude than in those from normoxic animals (Table 2) and were not affected by the addition of the substrate L-arg or the NOS blocker L-NNA (data not shown).

\subsection{Mechanical $\beta$-adrenergic response}

The increase in the developed tension of the normoxic papillary muscles in response to isoproterenol was: $48 \pm 10 \%, 42 \pm 8 \%$ and $47 \pm 4 \%$, for control, L-arg and L-NNA respectively (Fig. 5 a). On the contrary, the $\beta$-adrenergic response of papillary muscles from $\mathrm{HH}$ was significantly higher when NOS substrate was added: $36 \pm 4 \%$, $64 \pm 6 \%$, and $46 \pm 5 \%$ for C, L-arg and L-NNA, respectively (Fig. 5b). Similar results were observed for the basal rates of contraction and relaxation (Table 3).

\subsection{Tolerance to hypoxia/reoxygenation}

After a period of $60 \mathrm{~min}$ of hypoxia and $30 \mathrm{~min}$ of reoxygenation the normoxic group recovered $51 \pm 4 \%, 60 \pm 1 \%$ and $57 \pm 3 \%$ of DT in control, L-arg and L-NNA, respectively, without significant differences between treatments (Fig. 6a). In rats submitted to HH for $48 \mathrm{~h}$ the recovery after $\mathrm{H} / \mathrm{R}$ was significantly higher than in normoxic rats whether in C $(78 \pm 6 \%)$ as in L-arg $(70 \pm 3 \%)$, and cardioprotection was lost (Fig. 6b) with the addition of NOS blocker (54 $\pm 1 \%$ ). Similar results were observed for the rates of contraction and relaxation (Table 4).

\subsection{Histological analysis}

Left ventricles of rats exposed to hypobaric hypoxia for $48 \mathrm{~h}$ presented slight modifications in their morphology when compared with those of normoxic rats. In particular, some evidence of capillary congestion in the hypoxic ventricle was observed (Fig. 7). No other remarkable changes were found. Histopathology analysis was performed in the papillary muscles which underwent the different specific treatments previously described (Fig. 1). After H/R, the papillary muscles from normoxic and hypoxic rats supplemented with an inhibitor of NOS, L-NNA, presented characteristic histological features of ischemia and muscle fiber stress: capillary congestion, edema, wavy myocardial fibers, contraction bands, hypereosinophilia and myocyte nuclei loss (Fig. 8, b and d). Papillary muscles of the normoxic group supplemented with L-arg showed evidence of cellular edema; in contrast, those from rats exposed to hypobaric hypoxia for $48 \mathrm{~h}$ were preserved when supplemented with L-arg (Fig. 8, a and c).

\section{Discussion}

We have previously reported that acclimatization of rats to sustained hypobaric hypoxia retarded age-associated decline in left ventricle mechanical activity and improved posthypoxic recovery, involving an increased NO production and NOS protein expression in 
(a)
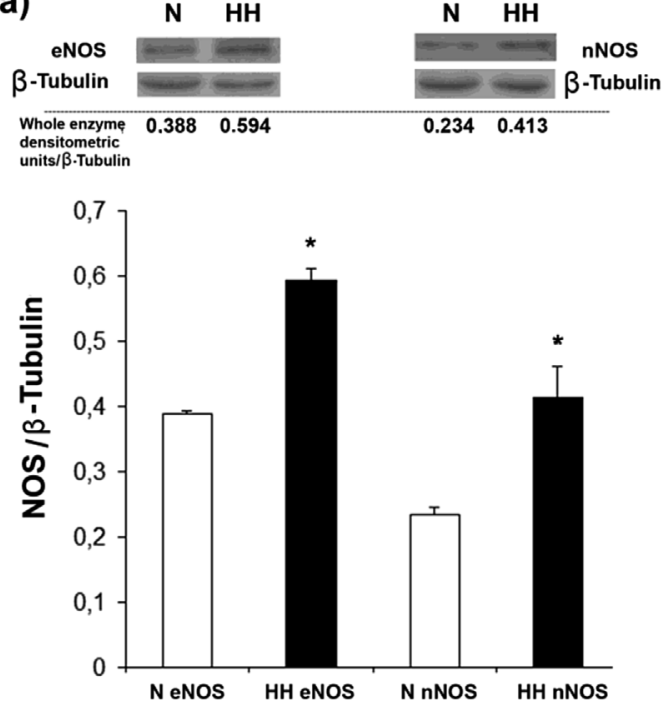

(b)

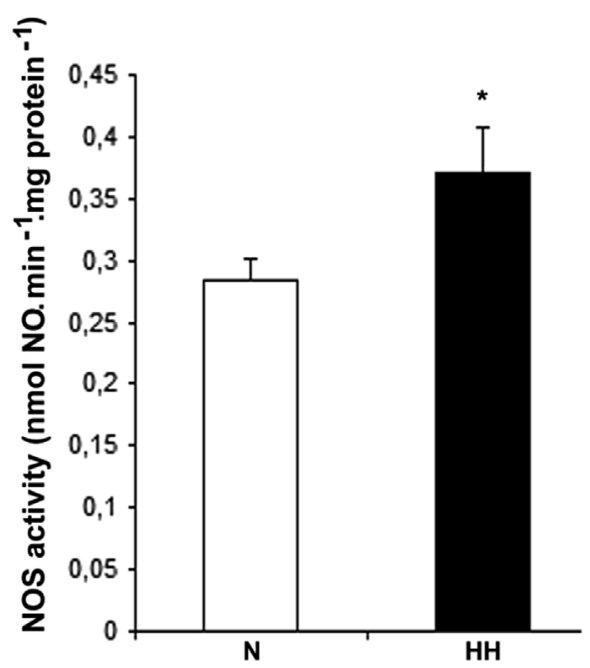

Fig. 3. (a) Left ventricle cytosolic NOS expression; (b) Left ventricle cytosolic NOS production. $\mathrm{N}$ : normoxic group; HH: hypobaric hypoxia $48 \mathrm{~h}$; ratio NOS/ $\beta$-Tubulin expressed in densitometric units. Values are means $\pm \mathrm{SE} ; * P<.05$ vs. $\mathrm{N}$ group.

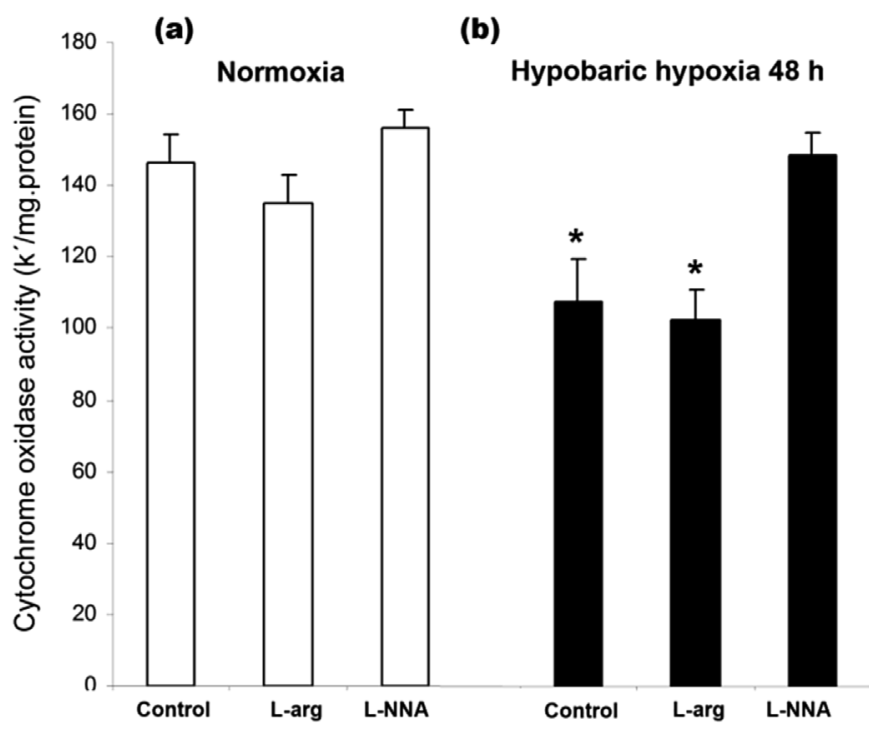

Fig. 4. Cytochrome oxidase activity evaluated in left ventricle mitochondria under conditions of maximal NO production (in the presence of L-arg), minimal NO production (in the presence of L-NNA) and control NO production (with no additions). Values are means $\pm \mathrm{SE} ; * P<.05$ vs. all groups.

Table 2

Basal contractile parameters of papillary muscles from rats submitted $48 \mathrm{~h}$ to $58.7 \mathrm{kPa}$ $(\mathrm{HH})$ and from their controls at $101.3 \mathrm{kPa}(\mathrm{N})$.

\begin{tabular}{llll}
\hline Group & $\begin{array}{l}\text { Developed tension } \\
\text { g.mm }\end{array}$ & $\begin{array}{l}\text { Maximal rate of } \\
\text { contraction } \\
\mathrm{g} \cdot \mathrm{mm}^{-2} \cdot \mathrm{s}^{-1}\end{array}$ & $\begin{array}{l}\text { Maximal rate of } \\
\text { relaxation } \\
\mathrm{g} \cdot \mathrm{mm}^{-2} \cdot \mathrm{s}^{-1}\end{array}$ \\
\hline $\mathrm{N}$ & $1,8 \pm 0,4$ & $24 \pm 4$ & $15 \pm 2$ \\
$\mathrm{HH}$ & $1,8 \pm 0,4$ & $23 \pm 4$ & $16 \pm 2$
\end{tabular}

Values are means $\pm S E ; n=10$ rats in each group (20 papillary muscles).

mitochondrial fraction $[2,9,13]$. The present study shows that $48 \mathrm{~h}$ of acute exposure of young adult rats to $4400 \mathrm{~m}$ simulated altitude confers cardioprotection with the participation of cytosolic NO.

\subsection{Biological parameters}

After $48 \mathrm{~h}$ of exposure of rats to $4400 \mathrm{~m}$ simulated altitude the body weight decreased $7 \%$. The weight loss has been associated to the HIF (a)

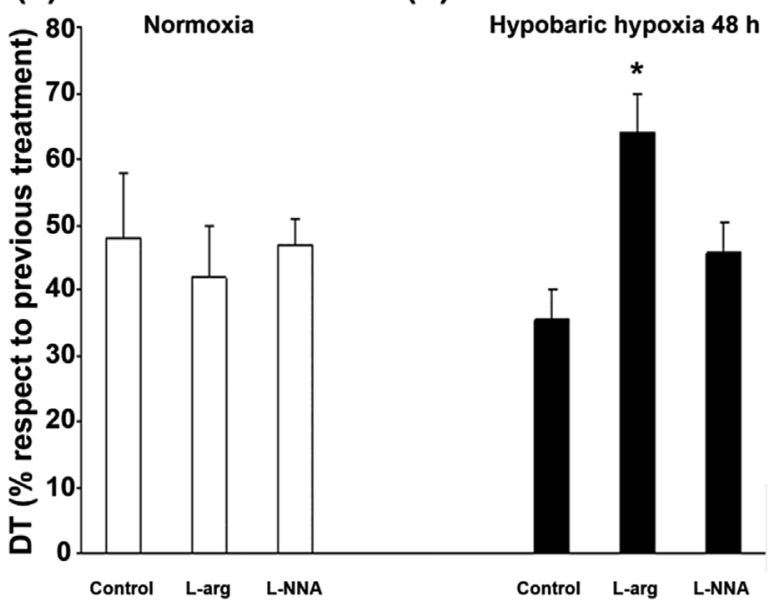

Fig. 5. Response to isoproterenol (ISO) of papillary muscles from normoxic (a) and $\mathrm{HH}$ rats (b) in percentage increase of baseline values. Values are means \pm SE. ${ }^{*} P<0,5$ vs. Control and L-NNA. DT: developed tension.

Table 3

Percentage of increase in basal rates of contraction and relaxation after $\beta$-adrenergic stimulation.

\begin{tabular}{lllll}
\hline Group & Parameter & Control & L-arg & L-NNA \\
\hline Normoxia & $+\mathrm{T}$ & $77 \pm 6$ & $71 \pm 4$ & $70 \pm 8$ \\
& $-\mathrm{T}$ & $135 \pm 15$ & $121 \pm 14$ & $128 \pm 17$ \\
Hypobaric & $+\mathrm{T}$ & $65 \pm 5$ & $102 \pm 14^{*}$ & $57 \pm 5$ \\
hypoxia & $-\mathrm{T}$ & $98 \pm 12$ & $142 \pm 11^{*}$ & $103 \pm 5$ \\
\hline
\end{tabular}

Values are means $\pm \mathrm{SE} ; * \mathrm{P}<.05$ vs. Control and L-NNA.

$[1,31]$, throughout a variation in the leptin levels, which impacts as a decrease of food intake, with a marked reduction in fat content [32,33]. Contradictory data on blood pressure changes at high altitude has been reported. In fact, while some authors described an increase in systemic blood pressure, others found no significant changes [34,35] as in our study. Increased arterial pressure after ascent to a similar high altitude in humans has been reported to the point that the use of $\beta$-blockers for sojourner travelers was recommended $[27,36]$. The species and protocols used could explain the different observations [23,37]. In humans, the climbing time, the low temperature, and psychophysical stress can stimulate the sympathetic nervous system [35,38], whereas in our 
(a)

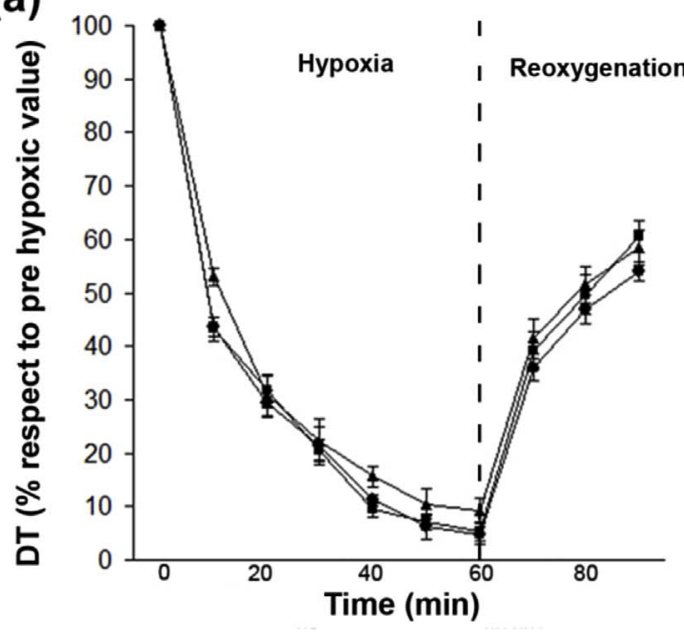

(b)

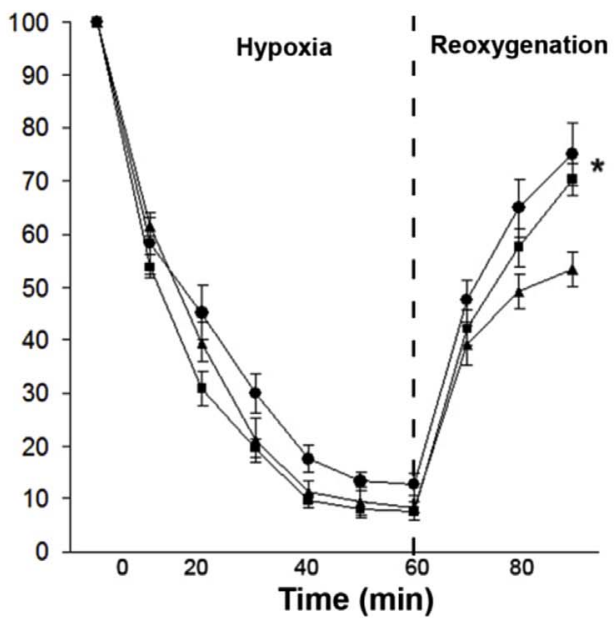

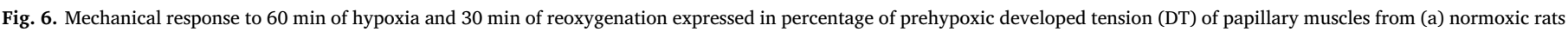

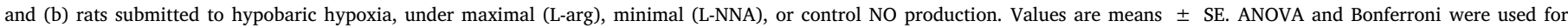
comparisons between groups. ${ }^{*} P<.05$, HH Control and HH L-arg vs. all groups.

Table 4

Recovery of maximal rates of contraction $(+\mathrm{T})$ and relaxation $(-\mathrm{T})$ after $60 \mathrm{~min} \mathrm{H}$ and $30 \mathrm{~min} \mathrm{R}$ in percentage of prehypoxic values.

\begin{tabular}{lllll}
\hline Group & Parameter & Control & L-arg & L-NNA \\
\hline Normoxia & $+\mathrm{T}$ & $63 \pm 5$ & $59 \pm 9$ & $67 \pm 5$ \\
& $-\mathrm{T}$ & $64 \pm 5$ & $60 \pm 5$ & $60 \pm 6$ \\
Hypobaric & $+\mathrm{T}$ & $82 \pm 6$ & $80 \pm 3$ & $58 \pm 2^{*}$ \\
hypoxia & $-\mathrm{T}$ & $82 \pm 6$ & $73 \pm 3$ & $56 \pm 4^{*}$
\end{tabular}

Values are means $\pm \mathrm{SE} ; * \mathrm{P}<.05$ vs. Control and L-arg.

experiment the sedentary life of the rats and the mild temperature $\left(22{ }^{\circ} \mathrm{C}\right)$ in the hypoxic chamber could have contributed to keep blood pressure unchanged. Moreover, it was reported that during the first few hours of exposure to hypoxia hypoxic vasodilation tends to override sympathetic vasoconstriction in the systemic circulation, resulting in an unchanged or slightly decreased systemic blood pressure [34,39].

\subsection{Expression of HIF-1 $\alpha$, NOS and NO production}

The expression of HIF-1 $\alpha$, which is recognized as the main regulator of oxygen homeostasis in the body in response to hypoxia stimulus, was found increased in this study. HIF regulates over 40 hypoxia-inducible genes including NOS isoforms [1]. In our previous work we showed that several weeks of exposure of initially immature rats to high altitude increased the production and expression of NO in the mitochondrial fraction $[9,13]$, where NO regulates $\mathrm{O}_{2}$ consumption [24,40,41]. At a systemic level, the main effect of NO is to bring up the peripheral vasodilation [3,42], promoting a better supply of oxygen to the tissues [1]. In the pulmonary system, it functions to counterbalance the tendency to develop pulmonary hypertension [43]. In the present study we evaluated the cytosolic NOS system, finding a significant increase in the expression of both constitutive isoforms, eNOS and nNOS, in left ventricles of HH rats. The high increased levels in the expression of NOS were not matched up by a similar equal level of NO production. This would indicate a difference between the expression and the enzymatic activation, which could be attributed to L-arg availability, $\mathrm{Ca}^{2+}$ transient and/or phosphorylation enzyme status $[44,45]$. The increased NO level production has been also reported in other experimental models and humans protocols, where NO modulates the degree of vasoconstriction at systemic and pulmonary levels $[46,47]$. On the other hand at mitochondrial level, the acute exposure to $\mathrm{HH}$, would not be enough to increase significantly the NOS expression as was previously found after chronic hypoxia $[9,13]$. The slight increase observed in nNOS may explain the decreased cytochrome oxidase activity in mitochondria from hypoxic rats, since this effect was not evident in the presence of LNNA. In vivo, cytosolic NO would diffuse within the mitochondria enhancing the effect on cytochrome oxidase activity.

\subsection{Basal contractile parameters}

Excitation-contraction coupling is driven by an ion channel mediated calcium cycle that produces myofilament contraction and relaxation, and NO synthesis by constitutive NOS is calcium dependent. The effect of NO on contractility is bimodal in a concentration dependent manner, and there are NOS isoform-specific responses within the heart [9]. The action of the NOS depends on its systemic and intracellular localization $[1,3,14]$. Inside papillary muscle NO modulates $\mathrm{L}-\mathrm{Ca}^{+2}$ and RyR channels directly by nitrosylation [14,23], modifying the levels of intracellular $\mathrm{Ca}^{+2}$, which determine the contractile myofibrils stage $[48,49]$. On the other hand, NO generated by mitochondrial NOS and/ or diffusing from cytosolic NOS, regulates oxygen consumption by the
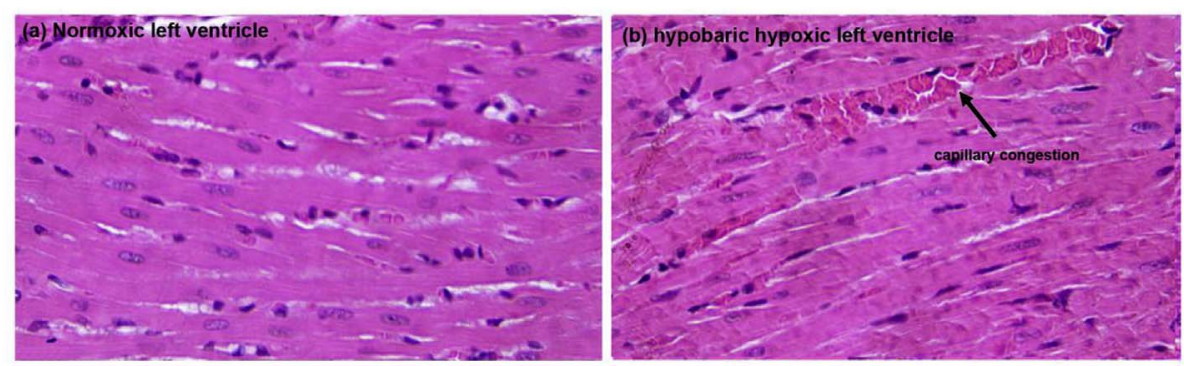

Fig. 7. Left ventricles belonging to $3 \mathrm{mo}$ old rats. Microphotographs of (a) preserved tissue of a normoxic rat, and (b) of a rat that was exposed to $48 \mathrm{~h}$ of hypobaric hypoxia, showing only slight morphologic changes such as capillary congestion (arrow). The tissues were stained with H\&E (40X). 

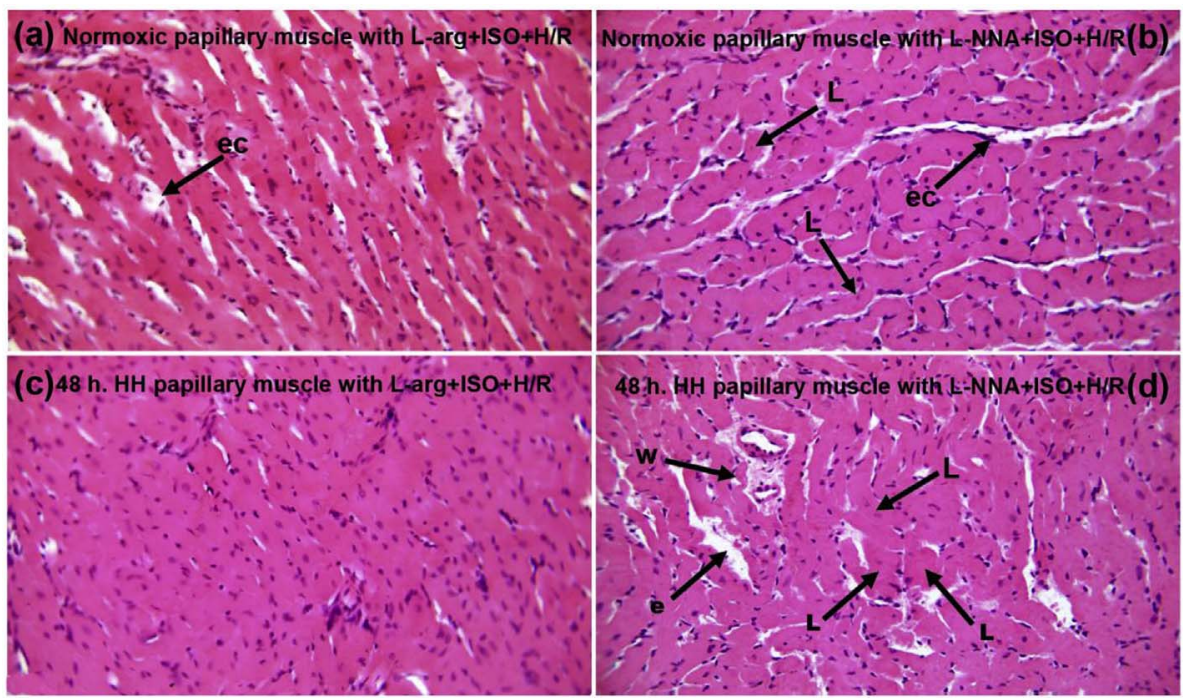

Fig. 8. Microphotographs of papillary muscles (PM) from 3 mo old rats. Each slide is labeled with the procedure the tissue underwent. (a) Normoxic PM in conditions of maximal production of NO (L-arg), plus isoproterenol (ISO), and $60 \mathrm{~min}$ of hypoxia and $30 \mathrm{~min}$ of reoxygenation (H/R). There is evidence of intercellular edema and congestion (ec). (b) Normoxic PM treated with an inhibitor of NOS (LNNA), ISO, and H/R. The tissue shows signs of edema and congestion (ec), and focal lack of myocardial nuclei (L). (c) Hypobaric hypoxic (HH) PM in conditions of maximal production of NO (L-arg), plus isoproterenol (ISO), and $60 \mathrm{~min}$ of hypoxia and $30 \mathrm{~min}$ of reoxygenation (H/R). Cardiac tissue is preserved. (d) HH PM treated with an inhibitor of NOS (L-NNA), ISO and H/R. The slide presents edema (e), focal lack of myocardial nuclei (L), and scarce wavy fibers (w). All samples were stained with H\&E (40X). respiratory mitochondrial chain $[24,50]$ extending the space of adequate tissue oxygenation away from the blood vessel [1]. These physiological strategies would contribute to increase the contractile efficiency (contractile function/oxygen consumption), preserving the mechanical activity. Furthermore, no remarkable changes were found in histological analysis of the hypoxic left ventricle except some evidence of capillary congestion. After chronic hypoxia, an increase in NO production and expression was associated to preservation of mechanical activity from age-associated decline [2,9,13].

\subsection{Mechanical $\beta$-adreneregic response}

The absence of differential response to isoproterenol stimulus in papillary muscles of normoxic animals after the addition of L-arg substrate or of NOS blocker indicates no interaction between NOS and $\beta$ adrenergic systems in a model without circulation or neuronal regulation, in contrast with what was reported in perfused heart [18]. After $48 \mathrm{~h}$ of exposure to simulated high altitude (HHC), the response to $\beta$ adrenergic stimulation remained the same as in normoxic muscles, probably because of the unchanged $\beta$-adrenergic system during the first hours of hypobaric treatment discussed above [34,39]. Conversely, Larg increased $\beta$-adrenergic response in $\mathrm{HH}$ papillary muscles. The intracellular increase of $\mathrm{Ca}^{2+}$ by $\beta$-stimulation could activate the overexpressed constitutive NOS, which is $\mathrm{Ca}^{2+}$ dependent. Such increased NO production could nitrosylate $\mathrm{L}-\mathrm{Ca}^{2+}$ and RyR channels [14,23], improving mechanical activity.

\subsection{Tolerance to hypoxia/reoxygenation}

In the present study, under normoxic conditions, the tolerance to acute $H / R$ was low and was unaffected by the NOS system or by $\beta$ -adrenergic stimulation. The recovery of the contractile parameters was similar to that found in our previous studies in normoxic rats $(\sim 57 \%)$ $[2,9]$. In agreement, the histological analysis revealed damage in the papillary muscles supplemented with either L-arg or L-NNA (edema, wavy myocardial fibers, and contraction bands), suggesting that the NOS and the $\beta$-adrenergic systems were unable to improve resistance to an $\mathrm{H} / \mathrm{R}$ episode in normoxic animals. The discrepancy between these findings and the cardioprotection conferred by $\beta$-adrenergic stimulation observed by other authors $[26,51]$ in normoxic rats could be attributed to resistance to $\mathrm{H} / \mathrm{R}$ of immature hearts [52,53]. Conversely, the high level of NOS activity in the HH group would allow a good preservation of the histological and mechanical conditions after acute H/R. The lack of improvements in the HH L-NNA subgroup sustains the involvement of NOS in the beneficial effects of acute exposure of rats to HH. The produced NO would improve the tolerance to $H / R$, via modulation of the mitochondrial transport chain and reduction of reactive oxygen species generation [54]. Nitric oxide inhibits cytochrome oxidase reversibly and competitively with oxygen. The observed increment of cytosolic NO levels as a consequences of higher expression of nNOS and eNOS in the hypoxic conditions would inhibit cytochrome oxidase activity, leaving oxygen available to diffuse and be used for other processes. Furthermore, via $S$-nitrosylation, NO could attenuate a number of adverse processes, such as apoptosis, inflammation, and opening of the mitochondrial permeability transition pore, and even stimulate protective processes like angiogenesis [25].

In conclusion, exposure of rats to acute hypobaric hypoxia increased cytosolic NOS expression and NO production in left ventricle associated to an improved tolerance of papillary muscles to hypoxia/reoxygenation. These findings support the idea that it is possible to achieve endogenous cardioprotection without changes in arterial pressure by acute simulated high altitude exposure. This allows considering a possible preventive therapeutic approach for cardiovascular hypoxic risk using short hypobaric hypoxia treatment or emulating the specific molecular pathways involved.

\section{Funding}

This work was supported by grants from: Consejo Nacional de Investigaciones Científicas y Técnicas (CONICET) Argentina PIP 0779 CO, PIP 1688, PIP 11220100100470 and 20020130100255 from University of Buenos Aires.

\section{Acknowledgments}

We are very grateful to MV Nora Paglia ${ }^{1}$ for the measurement of arterial blood pressure, and to Marisa Moriondo ${ }^{1}$ for the histological preparations. ${ }^{1}$ Institute of Cardiological Research, School of Medicine, University of Buenos Aires, National Research Council (ININCA, UBA, CONICET), 1122 Buenos Aires, Argentina.

\section{References}

[1] Costa, Nitric Oxide and Mitochondrial Adaptation to Hypobaric Hypoxia, Research Signpost, Kerala, India, 2007.

[2] P. La Padula, L.E. Costa, Effect of sustained hypobaric hypoxia during maturation and aging on rat myocardium. I. Mechanical activity, J. Appl. Physiol. 98 (2005) (1985) 2363-2369.

[3] E.B. Manukhina, H.F. Downey, R.T. Mallet, Role of nitric oxide in cardiovascular adaptation to intermittent hypoxia, Exp. Biol. Med. 231 (2006) 343-365. 
[4] L.E. Costa, Hepatic cytochrome P-450 in rats submitted to chronic hypobaric hypoxia, Am. J. Physiol. 259 (1990) C654-C659.

[5] L.E. Costa, S. Llesuy, A. Boveris, Active oxygen species in the liver of rats submitted to chronic hypobaric hypoxia, Am. J. Physiol. 264 (1993) C1395-C1400.

[6] L.E. Costa, G. Mendez, A. Boveris, Oxygen dependence of mitochondrial function measured by high-resolution respirometry in long-term hypoxic rats, Am. J. Physiol. 273 (1997) C852-C858.

[7] R. Bolli, Preconditioning: a paradigm shift in the biology of myocardial ischemia, Am. J. Physiol. Heart Circ. Physiol. 292 (2007) H19-H27.

[8] J. Neckar, B. Ostadal, F. Kolar, Myocardial infarct size-limiting effect of chronic hypoxia persists for five weeks of normoxic recovery, Physiol. Res. 53 (2004) 621-628.

[9] P. La Padula, J. Bustamante, A. Czerniczyniec, L.E. Costa, Time course of regression of the protection conferred by simulated high altitude to rat myocardium: correlation with mtNOS, J. Appl. Physiol. 105 (2008) (1985) 951-957.

[10] C.M. Fitzpatrick, Y. Shi, W.C. Hutchins, J. Su, G.J. Gross, B. Ostadal, J.S. Tweddell, J.E. Baker, Cardioprotection in chronically hypoxic rabbits persists on exposure to normoxia: role of NOS and KATP channels, Am. J. Physiol. Heart Circ. Physiol. 288 (2005) H62-H68.

[11] L. Xi, D. Tekin, E. Gursoy, F. Salloum, J.E. Levasseur, R.C. Kukreja, Evidence that NOS2 acts as a trigger and mediator of late preconditioning induced by acute systemic hypoxia, Am. J. Physiol. Heart Circ. Physiol. 283 (2002) H5-H12.

[12] P. Salvi, M. Revera, A. Faini, A. Giuliano, F. Gregorini, P. Agostoni, C.G. Becerra, G. Bilo, C. Lombardi, M.F. O'Rourke, G. Mancia, G. Parati, Changes in subendocardial viability ratio with acute high-altitude exposure and protective role of acetazolamide, Hypertension 61 (2013) 793-799.

[13] T. Zaobornyj, L.B. Valdez, P. La Padula, L.E. Costa, A. Boveris, Effect of sustained hypobaric hypoxia during maturation and aging on rat myocardium. II. mtNOS activity, J. Appl. Physiol. 98 (2005) (1985) 2370-2375.

[14] J.M. Hare, Nitric oxide and excitation-contraction coupling, J. Mol. Cell. Cardiol. 35 (2003) 719-729.

[15] J.E. Baker, Oxidative stress and adaptation of the infant heart to hypoxia and ischemia, Antioxidants Redox Signal. 6 (2004) 423-429.

[16] J.E. Baker, P. Holman, B. Kalyanaraman, O.W. Griffith, K.A. Pritchard Jr., Adaptation to chronic hypoxia confers tolerance to subsequent myocardial ischemia by increased nitric oxide production, Ann. N. Y. Acad. Sci. 874 (1999) 236-253.

[17] F. Kolar, B. Ostadal, Molecular mechanisms of cardiac protection by adaptation to chronic hypoxia, Physiol. Res. 53 (Suppl 1) (2004) S3-S13.

[18] J.L. Balligand, Regulation of cardiac beta-adrenergic response by nitric oxide, Cardiovasc. Res. 43 (1999) 607-620.

[19] V. Conti, G. Russomanno, G. Corbi, V. Izzo, C. Vecchione, A. Filippelli, Adrenoreceptors and nitric oxide in the cardiovascular system, Front. Physiol. 4 (2013) 321.

[20] P.M. Vanhoutte, Y. Gao, Beta blockers, nitric oxide, and cardiovascular disease, Curr. Opin. Pharmacol. 13 (2013) 265-273.

[21] L.R. Queen, A. Ferro, Beta-adrenergic receptors and nitric oxide generation in the cardiovascular system, Cell. Mol. Life Sci. 63 (2006) 1070-1083.

[22] S.R. Martin, K. Emanuel, C.E. Sears, Y.H. Zhang, B. Casadei, Are myocardial eNOS and nNOS involved in the beta-adrenergic and muscarinic regulation of inotropy? A systematic investigation, Cardiovasc. Res. 70 (2006) 97-106.

[23] R. Rastaldo, P. Pagliaro, S. Cappello, C. Penna, D. Mancardi, N. Westerhof, G. Losano, Nitric oxide and cardiac function, Life Sci. 81 (2007) 779-793.

[24] G.C. Brown, V. Borutaite, Nitric oxide and mitochondrial respiration in the heart Cardiovasc. Res. 75 (2007) 283-290.

[25] J.W. Calvert, D.J. Lefer, Role of beta-adrenergic receptors and nitric oxide signaling in exercise-mediated cardioprotection, Physiology 28 (2013) 216-224 Bethesda.

[26] R. Salie, J.A. Moolman, A. Lochner, The role of beta-adrenergic receptors in the cardioprotective effects of beta-preconditioning (betaPC), Cardiovasc. Drugs Ther. 25 (2011) 31-46.

[27] G. Bilo, F.C. Villafuerte, A. Faini, C. Anza-Ramirez, M. Revera, A. Giuliano, S. Caravita, F. Gregorini, C. Lombardi, E. Salvioni, J.L. Macarlupu, D. Ossoli, L. Landaveri, M. Lang, P. Agostoni, J.M. Sosa, G. Mancia, G. Parati, Ambulatory blood pressure in untreated and treated hypertensive patients at high altitude: the High Altitude Cardiovascular Research-Andes study, Hypertension 65 (2015) $1266-1272$.

[28] E. Donegani, P. Paal, T. Kupper, U. Hefti, B. Basnyat, A. Carceller, P. Bouzat, R. van der Spek, D. Hillebrandt, Drug use and misuse in the mountains: a UIAA MedCom consensus guide for medical professionals, High Alt. Med. Biol. 17 (2016) 157-184.

[29] M.E. Murphy, E. Noack, Nitric oxide assay using hemoglobin method, Meth.
Enzymol. 233 (1994) 240-250.

[30] A. Boveris, S.L. Arnaiz, J. Bustamante, S. Alvarez, L. Valdez, A.D. Boveris, A. Navarro, Pharmacological regulation of mitochondrial nitric oxide synthase, Meth. Enzymol. 359 (2002) 328-339.

[31] G.L. Semenza, O2-regulated gene expression: transcriptional control of cardiorespiratory physiology by HIF-1, J. Appl. Physiol. 96 (2004) (1985) 1173-7; discussion 1170-1172.

[32] L.E. Costa, I.H. Martin, J.C. Macome, A.C. Taquini, Effect of chronic hypobaric hypoxia on the growth and body composition of the rat, Medicina 39 (1979) 604-610.

[33] T. Debevec, E.J. Simpson, I.B. Mekjavic, O. Eiken, I.A. Macdonald, Effects of prolonged hypoxia and bed rest on appetite and appetite-related hormones, Appetite 107 (2016) 28-37.

[34] P. Bartsch, J.S. Gibbs, Effect of altitude on the heart and the lungs, Circulation 116 (2007) 2191-2202.

[35] G. Bilo, G. Caldara, K. Styczkiewicz, M. Revera, C. Lombardi, A. Giglio, A. Zambon, G. Corrao, A. Faini, M. Valentini, G. Mancia, G. Parati, Effects of selective and nonselective beta-blockade on 24-h ambulatory blood pressure under hypobaric hypoxia at altitude, J. Hypertens. 29 (2011) 380-387.

[36] R. Hainsworth, M.J. Drinkhill, M. Rivera-Chira, The autonomic nervous system at high altitude, Clin. Auton. Res. 17 (2007) 13-19.

[37] T.V. Serebrovskaya, E.B. Manukhina, M.L. Smith, H.F. Downey, R.T. Mallet, Intermittent hypoxia: cause of or therapy for systemic hypertension? Exp. Biol. Med. 233 (2008) 627-650.

[38] R. Hainsworth, M.J. Drinkhill, Cardiovascular adjustments for life at high altitude, Respir. Physiol. Neurobiol. 158 (2007) 204-211.

[39] R. Naeije, Physiological adaptation of the cardiovascular system to high altitude, Prog. Cardiovasc. Dis. 52 (2010) 456-466.

[40] A. Cassina, R. Radi, Differential inhibitory action of nitric oxide and peroxynitrite on mitochondrial electron transport, Arch. Biochem. Biophys. 328 (1996) 309-316.

[41] J.J. Poderoso, M.C. Carreras, C. Lisdero, N. Riobo, F. Schopfer, A. Boveris, Nitric oxide inhibits electron transfer and increases superoxide radical production in rat heart mitochondria and submitochondrial particles, Arch. Biochem. Biophys. 328 (1996) 85-92.

[42] L.J. Ignarro, Nitric Oxide: Biology and Pathobiology, Academic Press, New York, 2000 .

[43] C.A. Eichstaedt, T. Antao, A. Cardona, L. Pagani, T. Kivisild, M. Mormina, Genetic and phenotypic differentiation of an Andean intermediate altitude population, Phys. Rep. 3 (2015).

[44] I. Fleming, Molecular mechanisms underlying the activation of eNOS, Pflugers Arch 459 (2010) 793-806.

[45] U. Forstermann, W.C. Sessa, Nitric oxide synthases: regulation and function, Eur. Heart J. 33 (2012) 829-37, 837a-837d.

[46] C.M. Beall, D. Laskowski, S.C. Erzurum, Nitric oxide in adaptation to altitude, Free Radic. Biol. Med. 52 (2012) 1123-1134.

[47] E. Clementi, G.C. Brown, N. Foxwell, S. Moncada, On the mechanism by which vascular endothelial cells regulate their oxygen consumption, Proc Natl Acad Sci U S A 96 (1999) 1559-1562.

[48] G. Csordas, C. Renken, P. Varnai, L. Walter, D. Weaver, K.F. Buttle, T. Balla, C.A. Mannella, G. Hajnoczky, Structural and functional features and significance of the physical linkage between ER and mitochondria, J. Cell Biol. 174 (2006) 915-921.

[49] L. Xu, J.P. Eu, G. Meissner, J.S. Stamler, Activation of the cardiac calcium release channel (ryanodine receptor) by poly-S-nitrosylation, Science 279 (1998) 234-237.

[50] V. Borutaite, G.C. Brown, Nitric oxide induces apoptosis via hydrogen peroxide, but necrosis via energy and thiol depletion, Free Radic. Biol. Med. 35 (2003) 1457-1468.

[51] P.E. Penson, W.R. Ford, E.J. Kidd, K.J. Broadley, Activation of beta-adrenoceptors mimics preconditioning of rat-isolated atria and ventricles against ischaemic contractile dysfunction, Naunyn Schmiedebergs Arch Pharmacol 378 (2008) 589-597.

[52] B. Ost'adal, I. Ost'adalova, L. Skarka, F. Kolar, J. Kopecky, Ischemic injury of the developing heart, Exp. Clin. Cardiol. 7 (2002) 93-98.

[53] B. Ostadal, I. Ostadalova, N.S. Dhalla, Development of cardiac sensitivity to oxygen deficiency: comparative and ontogenetic aspects, Physiol. Rev. 79 (1999) 635-659.

[54] S. Shiva, M.N. Sack, J.J. Greer, M. Duranski, L.A. Ringwood, L. Burwell, X. Wang, P.H. MacArthur, A. Shoja, N. Raghavachari, J.W. Calvert, P.S. Brookes, D.J. Lefer, M.T. Gladwin, Nitrite augments tolerance to ischemia/reperfusion injury via the modulation of mitochondrial electron transfer, J. Exp. Med. 204 (2007) 2089-2102. 